\title{
Experimental and numerical investigation of the sintering rate of snow
}

\author{
Alec VAN HERWIJNEN, ${ }^{1,2}$ Daniel A. MILLER, ${ }^{1}$ \\ ${ }^{1}$ Department of Civil Engineering, Montana State University, Bozeman, MT, USA \\ E-mail: vanherwijnen@slf.ch \\ ${ }^{2}$ WSL Institute for Snow and Avalanche Research SLF, Davos, Switzerland
}

\begin{abstract}
Sintering rates in snow were investigated by measuring changes in penetration resistance with time and by using a numerical snow metamorphism model. Periodic Snow Micro Penetrometer (SMP) measurements were performed on uniform snow samples covering a wide range of densities. The mean penetration resistance of snow increased with time according to a power law with an average exponent of 0.18. Simulated changes in the bond-to-grain ratio for simplified spherical ice grains followed a power law with an average exponent of 0.18 , showing that the mean penetration resistance, as measured with the SMP, closely relates to bond-to-grain ratio in snow. For lower-density snow samples, consisting mostly of dendritic snow morphologies, the measured increase in penetration resistance was lower. This is likely the result of two competing processes: (1) strengthening of the snow sample due to the creation and growth of bonds and (2) weakening of the snow sample due to the formation of unbonded small rounded particles at the expense of larger dendritic forms. On the other hand, the rate of increase in penetration resistance for snow samples consisting of closely packed depth hoar was similar to that of rounded grains.
\end{abstract}

\section{INTRODUCTION}

Snow on the ground is generally encountered at temperatures close to its melting point. Snow is therefore a material which is thermodynamically active and continuously changing. Under isothermal conditions, individual snow grains move towards a spherical shape, while at the same time intergranular bonds form, reducing the total surface area of the system. The formation of bonds between ice grains is a process called sintering and leads to increased strength (for a comprehensive review of sintering of snow and ice see Blackford, 2007). Sintering of snow has various practical implications, from the gradual hardening of groomed ski runs or avalanche debris to the 'healing' of collapsed weak layers and building a perfect snowman.

The driving mechanism for the rapid (sub-second) formation of the initial bond between particles in contact is believed to be the freezing of a liquid layer in the contact region (Szabo and Schneebeli, 2007). However, after a short time when the initial bonds have formed, other processes contribute to sintering. Since snow is composed of crystalline particles, several potential mass transport mechanisms exist, including vapor diffusion, surface diffusion, grain boundary diffusion and plastic flow. Each mechanism conforms to a power law (Kuczynski, 1949):

$$
\left(\frac{r_{\mathrm{b}}}{r_{\mathrm{g}}}\right)^{n}=\frac{B(T)}{r_{\mathrm{g}}^{m}} t
$$

where $t$ is time, $B(T)$ is a temperature-dependent function which captures material and geometric properties, $r_{\mathrm{g}}$ is the grain radius, $r_{\mathrm{b}}$ is the bond radius, and $m$ and $n$ are integers that depend upon the mass transport mechanism. Studies of ice sintering were initiated by Kingery (1960) who measured neck growth rates between two ice spheres starting within a few minutes and extending to several hours. Since then, sintering has been investigated at timescales ranging from subsecond (Szabo and Schneebeli, 2007) to centuries (e.g. Gow, 1975). Most of the experimental studies have focused on bond growth between artificially created ice spheres using light microscopy (e.g. Kingery, 1960), computed tomography (CT; Kaempfer and Schneebeli, 2007), scanning electron microscope (SEM; Chen and Baker, 2010) or by measuring the force required to separate two ice spheres which have been in contact for a certain amount of time (e.g. Szabo and Schneebeli, 2007). Recently, Chen and Baker (2010) experimentally investigated bond formation between ice spheres by affecting the water vapor transport in the pore spaces. Using CT and a SEM, they found accelerated neck growth under temperature gradient conditions where the excess vapor pressure was higher. Fine protrusions have been found to grow from the vapor phase on the ice grain surfaces and eventually form necks (Adams and others, 2008; Chen and Baker, 2010). Colbeck (1998) applied a grain boundary diffusion model to ice sintering to describe grain boundary grooves, but did not provide physical evidence of grain boundary diffusion. Adams and others (2001) identified a 'grain boundary ridge' between ice grains using a SEM. Their theoretical development described a potential grain boundary diffusion scenario, but did not assess its significance. The prevailing consensus, over at least the last 30 years, is that for timescales on the order of hours to days, vapor diffusion is the primary sintering mechanism for spherical ice grains (e.g. Hobbs and Mason, 1964; Blackford, 2007; Adams and others, 2008; Chen and Baker, 2010). The assumption in this study is that while other mechanisms are simultaneously at work, vapor diffusion is dominant on the timescales of our experiments. The only exception is the potential short-term contribution of surface diffusion under very specific temperature and geometrical conditions (Maeno and Ebinuma, 1983). Hobbs and Mason (1964) showed that for vapor transport in snow $n=5$ and $m=3$, such that the bond-to-grain ratio should change with time according to a power law $t^{1 / 5}$. 
Table 1. Overview of experimental parameters. GT: grain type (decomposed and fragmented particles (DF), rounded grains (RG) and depth hoar $(\mathrm{DH})$ ) according to Fierz and others (2009) and observed mean grain size $(\mathrm{mm})$ in parentheses; $\rho_{\text {snow: }}$ snow density; $t_{\text {end }}$ : time of the last SMP measurements relative to the reference measurement; $b$ : sintering rate from SMP measurements and $95 \%$ confidence interval; $\left(r_{\mathrm{b}} / r_{\mathrm{g}}\right)_{\text {ini }}$ : initial bond-to-grain ratio used in the model; $b_{\text {model }}:$ sintering rate from model. Snow samples marked with an asterisk were prepared with artificially created snow

\begin{tabular}{|c|c|c|c|c|c|c|}
\hline Test & GT & $\begin{array}{c}\rho_{\text {snow }} \\
\mathrm{kg} \mathrm{m}^{-3}\end{array}$ & $\begin{array}{l}t_{\text {end }} \\
\min \end{array}$ & $b$ & $\left(r_{\mathrm{b}} / r_{\mathrm{g}}\right)_{\text {ini }}$ & $b_{\text {model }}$ \\
\hline$A^{*}$ & DF (0.75) & 104 & 321 & $0.07 \pm 0.03$ & 0.045 & 0.16 \\
\hline $\mathrm{B}^{*}$ & DF (0.75) & 132 & 316 & $0.10 \pm 0.04$ & 0.035 & 0.18 \\
\hline$C^{*}$ & DF (1) & 152 & 346 & $0.11 \pm 0.07$ & 0.026 & 0.19 \\
\hline $\mathrm{D}^{*}$ & RG (0.5) & 200 & 289 & $0.18 \pm 0.04$ & 0.029 & 0.19 \\
\hline $\mathrm{E}^{*}$ & DF (0.5) & 201 & 320 & $0.15 \pm 0.06$ & 0.045 & 0.18 \\
\hline $\mathrm{F}^{*}$ & RG (0.75) & 203 & 326 & $0.17 \pm 0.06$ & 0.031 & 0.18 \\
\hline G & RG (0.5) & 340 & 320 & $0.18 \pm 0.02$ & 0.032 & 0.19 \\
\hline $\mathrm{H}$ & RG (0.25) & 348 & 458.5 & $0.20 \pm 0.02$ & 0.060 & 0.18 \\
\hline I & RG (0.25) & 354 & 447 & $0.20 \pm 0.04$ & 0.051 & 0.18 \\
\hline J & $\mathrm{DH}(1)$ & 356 & 316 & $0.23 \pm 0.06$ & 0.025 & 0.19 \\
\hline K & RG (0.25) & 357 & 427 & $0.22 \pm 0.03$ & 0.055 & 0.18 \\
\hline L & $\mathrm{DH}(1)$ & 375 & 320 & $0.19 \pm 0.05$ & 0.035 & 0.17 \\
\hline $\mathrm{N}$ & $\mathrm{DH}(1)$ & 377 & 320 & $0.23 \pm 0.06$ & 0.025 & 0.19 \\
\hline $\mathrm{O}$ & $\mathrm{DH}(1)$ & 377 & 319 & $0.24 \pm 0.07$ & 0.030 & 0.18 \\
\hline$P$ & RG (0.5) & 380 & 405 & $0.28 \pm 0.03$ & 0.031 & 0.19 \\
\hline Q & $\mathrm{DH}(1)$ & 387 & 303 & $0.13 \pm 0.04$ & 0.046 & 0.14 \\
\hline $\mathrm{R}$ & RG (0.25) & 400 & 474 & $0.19 \pm 0.03$ & 0.056 & 0.18 \\
\hline
\end{tabular}

While previous studies have provided valuable insight into the physics governing ice sintering, the samples used were not necessarily representative of naturally occurring snow. Birkeland and others (2006) reported strength measurements after accidentally fracturing a weak layer during avalanche fieldwork. Compared to the pre-collapse values, the shear strength measurements after collapse were lower, but sintering occurred over time and the weak layer became stronger. Such measurements on natural snow remain extremely scarce and, thus far, sintering rates in natural snow remain largely unknown.

In this study, sintering rates in snow are investigated by measuring changes in penetration resistance of snow over time. Results from laboratory experiments are presented where uniform snow samples were monitored by performing periodic measurements using the Snow Micro Penetrometer (Schneebeli and Johnson, 1998). Furthermore, snow sample bond growth rates were simulated using a numerical snow metamorphism model (Miller and others, 2003; Miller and Adams, 2009). The objectives of the current study are: (1) to establish a relationship between the growth of bonds in snow and the penetration resistance and (2) to determine sintering rates for snow covering a range of densities and grain types typically observed in a natural snow cover.

\section{EXPERIMENTAL METHODS}

The Snow Micro Penetrometer (SMP) was used to measure the penetration resistance of snow samples. The SMP consists of a probe which is driven into the snow by a motor at a constant speed of $\sim 20 \mathrm{~mm} \mathrm{~s}^{-1}$ (Schneebeli and Johnson, 1998). The movable cone-shaped tip, with a diameter of $5 \mathrm{~mm}$ and an included angle of $60^{\circ}$, transfers changes in penetration resistance to a piezoelectric load sensor with a range of $0-42 \mathrm{~N}$. Force measurements are recorded at a sampling rate of $5 \mathrm{kHz}$, resulting in a vertical measurement resolution of $4 \mu \mathrm{m}$. Note that while the relation between SMP force signals and the mechanical properties of snow is not yet fully understood, a theory has been developed to derive microstructural snow properties from SMP force signals (Johnson and Schneebeli, 1999; Marshall and Johnson, 2009; Löwe and van Herwijnen, 2012).

Experiments were conducted in a cold room, where the relative humidity was kept around $50 \%$ and the temperature at $-10^{\circ} \mathrm{C}$. A rectangular box $60 \mathrm{~cm}$ long, $10 \mathrm{~cm}$ wide and $9 \mathrm{~cm}$ deep was filled with sieved snow to form a homogeneous snow sample. Mean snow sample densities, determined by weighing the entire sample, ranged from 105 to $400 \mathrm{~kg} \mathrm{~m}^{-3}$, similar to typical seasonal snow covers (Table 1). Low-density snow samples (samples A-F) were created with snow produced in a simple snowmaker that is a larger version of a snowmaker developed by Bones and Adams (2009), using a similar approach to Nakamura (1978). The snowmaker consists of a heated water reservoir kept at a temperature of $\sim 25^{\circ} \mathrm{C}$ in a cold room environment at $-25^{\circ} \mathrm{C}$. The humid air above the water is transported by cross-flow fans into a chimney at ambient temperature where the vapor precipitates on thin wires which serve as growth nuclei. In this way, low-density snow was created which consisted mainly of dendritic snow grains. Using a sieve with a mesh size of $4.75 \mathrm{~mm}$ the snow was sieved into the box. Higher-density snow samples were created by sieving natural snow into the box using a sieve with a mesh of $2 \mathrm{~mm}$.

An initial reference SMP measurement was performed immediately after the box was filled with snow (within 1 or 2 min). Thereafter, SMP measurements were performed at increasing time intervals up to 5-8hours (Table 1). To determine changes in penetration resistance with time, the mean penetration resistance $f(t)$ for each SMP measurement was computed. It was calculated as the depth-averaged penetration resistance from the snow surface to the end of the force signal. Since the initial SMP force signals were 
recorded in the air (as the tip of the probe moved towards the snow surface), the location of the snow surface was automatically determined using a method described in van Herwijnen and others (2009). Changes in penetration resistance with time were then considered relative to the reference SMP measurement. Results are thus shown as the dimensionless quantity $F(t)$ which is the mean penetration resistance relative to the mean of the reference SMP measurement: $F(t)=f(t) / f\left(t_{0}\right)$, with $t$ the elapsed time since the reference SMP measurement was made at time $t_{0}$. The rate of increase in penetration resistance with time, a proxy for the sintering rate, was then determined by the exponent $b$ of the power law $F(t)=a t^{b}$.

\section{NUMERICAL MODEL}

A numerical snow metamorphism model, developed by Miller and others (2003), was used to simulate bond growth rates of the snow samples. The physical processes are simulated on simplified spherical ice grains, interconnecting bond and pore-space geometries. The conservation of vapor mass in the pore space and heat flux in the ice via conduction are included. The conservation equations are coupled with heat and mass transfer through phase change at the ice/pore interface and include ice surface energies. The resulting coupled nonlinear differential equations are solved numerically by finite-difference methods of the discretized ice and pore network. Miller and Adams (2009) extended the model to include kinetic growth by implementing spiral defect propagation theory on simple faceted grain geometry, but this module is not utilized here due to lack of significant temperature gradients in the experiments. With an initial microstructural geometry (grain size, density and bond-tograin ratio), the model simulates metamorphism and predicts the changes in grain, bond and pore geometry. In a macroscopically isothermal environment, the model predicts bond growth due to sintering from the vapor phase. Miller and others (2003) showed that the model adequately reproduces the behavior of rounded snow morphologies.

We hypothesize that the increase in relative penetration resistance with time is in large part due to the growth of bonds between grains. Changes in measured penetration resistance were therefore compared to the modeled increase in bond-to-grain ratio. Modeled results are shown as the dimensionless quantity $R(t)$ which is the mean bond-tograin ratio relative to its initial value: $R(t)=r_{\mathrm{b}}(t) /$ $r_{\mathrm{g}}(t) /\left(r_{\mathrm{b}} / r_{\mathrm{g}}\right)_{\text {ini }}$. The required model inputs are temperature $T$, density $\rho_{\text {snow, }}$ initial grain radius $r_{\mathrm{g}}$, ini and initial bond-tograin ratio $\left(r_{\mathrm{b}} / r_{\mathrm{g}}\right)_{\text {ini }}$. The temperature was constant for all experiments $\left(T=-10^{\circ} \mathrm{C}\right)$, and $\rho_{\text {snow }}$ was measured for each snow sample (Table 1 ). For $r_{\mathrm{g} \text {, ini }}$ the average grain radius was determined using an optical microscope $(10 \times$ magnification) at the start of the experiment, similar to standard field observations (Fierz and others, 2009). The remaining variable $\left(r_{\mathrm{b}} / r_{\mathrm{g}}\right)_{\text {ini }}$ could not be measured. Hobbs and Mason (1964) reported measured ratios larger than 0.1. However, the sintering progressed so rapidly that very small bond-tograin ratios were not visually captured. Note that these initial bonds likely form due to other processes besides vapor diffusion to the bond surface (Szabo and Schneebeli, 2007). The modeled increase in bond-to-grain ratio followed a power law of the form $R(t)=a_{\text {model }} t^{b_{\text {model }}}$, and the modeled sintering rate was determined by the exponent $b_{\text {model }}$. Since there are no published measurements on

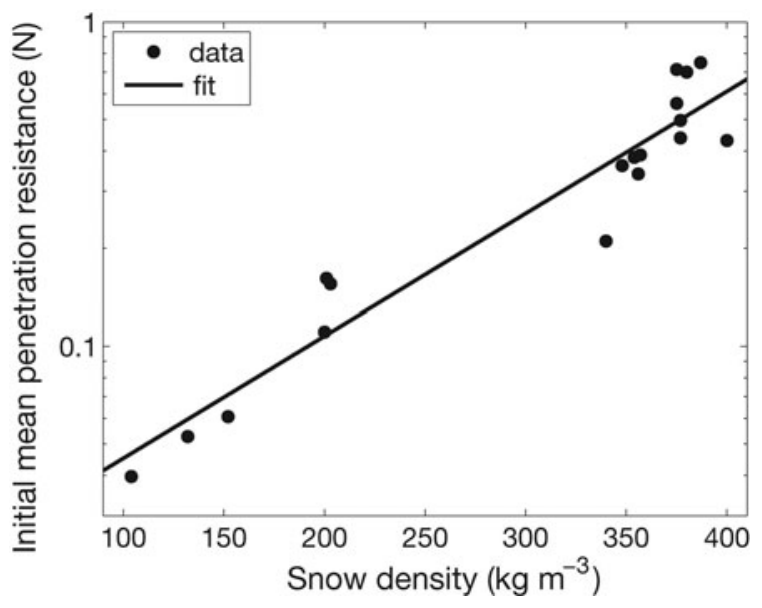

Fig. 1. Initial mean penetration resistance $f\left(t_{0}\right)$ with snow density $\rho_{\text {snow. }}$. Measured data (circles) and an empirical fit $f\left(t_{0}\right)=0.02 \mathrm{e}^{0.009 \rho_{\text {snow }}}$ (line) are shown.

typical bond-to-grain ratios for freshly sieved snow, $\left(r_{\mathrm{b}} / r_{\mathrm{g}}\right)_{\text {ini }}$ was estimated by fitting $R(t)$ to $F(t)$ using least-squares optimization. All $\left(r_{\mathrm{b}} / r_{\mathrm{g}}\right)_{\text {ini }}$ values used were reasonable and small (3-6\%; Table 1).

\section{RESULTS}

At the beginning of every measurement series (A-R), a reference SMP measurement was performed. The mean penetration resistance $f\left(t_{0}\right)$ of these reference measurements increased with density (Fig. 1). The correlation between $\rho_{\text {snow }}$ and $\ln \left(f\left(t_{0}\right)\right)$ was highly significant (Pearson $\left.r=0.96, p=10^{-9}\right)$, and the empirical relationship $f\left(t_{0}\right)=0.02 \mathrm{e}^{0.009 \rho_{\text {snow }}}$ provided a good fit to the experimental data (line in Fig. 1). Note that Pearson product-moment linear correlation is used to determine associations between variables. The correlation coefficient $r$ ranges from -1 (perfect negative correlation) to 1 (perfect positive correlation) and is considered significant for $p<0.05$.

As snow was allowed to sinter, the penetration resistance of the snow samples increased with time. For example, for snow sample $\mathrm{K}$, which consisted of rounded grains (mean diameter $0.25 \mathrm{~mm}$ ) with a density of $357 \mathrm{~kg} \mathrm{~m}^{-3}$, the mean penetration resistance increased more than threefold, from $0.4 \mathrm{~N}$ to $1.4 \mathrm{~N}$, within $\sim 7$ hours (Fig. 2a). Despite scatter in the measured force signals with depth, a trend in $F(t)$ with time was evident (Fig. 2b). Note that fluctuations in the force signals did not increase with time, as the coefficient of variation, i.e. the ratio of the standard deviation to the mean of the force signal, was essentially constant throughout all experiments (not shown). The sintering rate $b$ for this experiment was $0.22 \pm 0.03$, while the corresponding modeled sintering rate of 0.18 was somewhat lower (Table 1 ). An overview of $b$ and $b_{\text {model }}$ for all experiments is given in Table 1. Overall, the measured sintering rate averaged $0.18 \pm 0.05$, in good accordance with the mean $b_{\text {model }}$ of $0.18 \pm 0.01$. The largest differences between measured and modeled sintering rates were generally observed for snow samples with a density less than $200 \mathrm{~kg} \mathrm{~m}^{-3}$.

The measured sintering rates depended on snow density and grain type. Low-density snow samples, consisting of decomposed and fragmented particles (DF), were associated with the lowest measured sintering rates (Fig. 3). Therefore, 

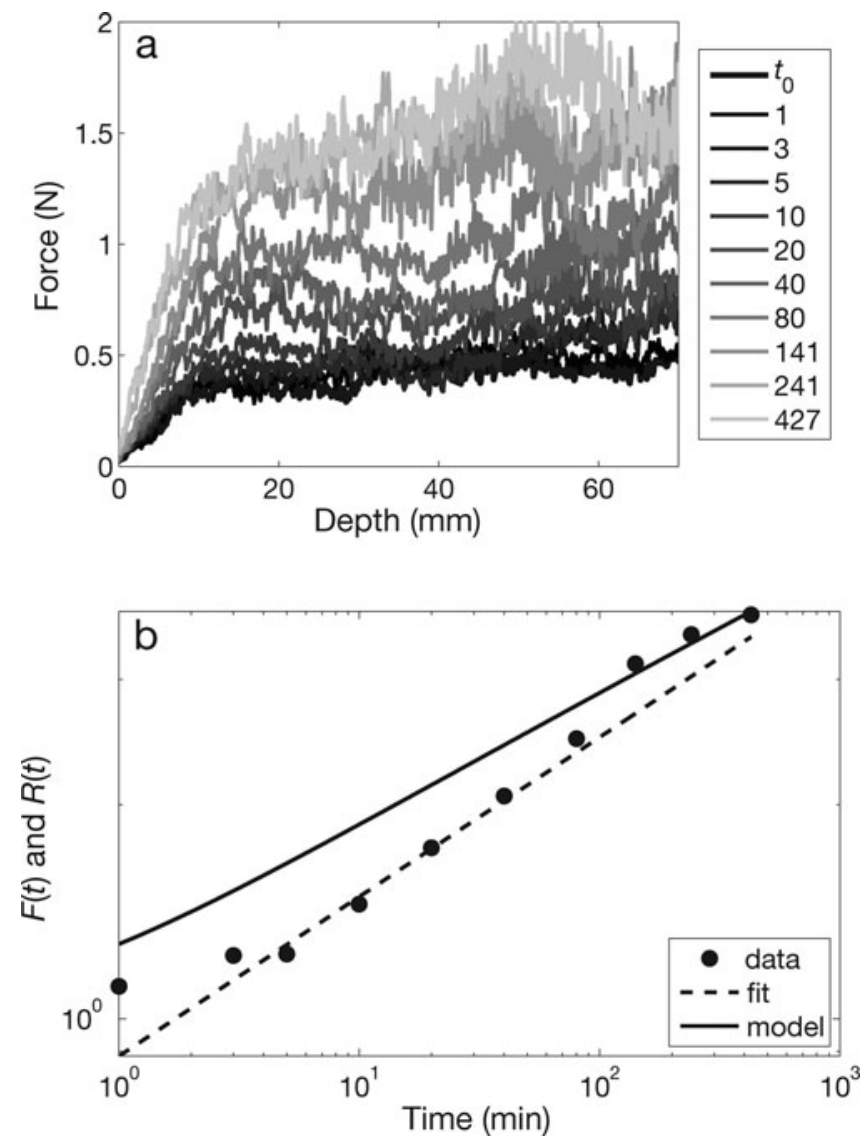

Fig. 2. Penetration resistance of a representative snow sample (sample $\mathrm{K}$ in Table 1) with time. (a) 50-point moving average of the measured force signals with depth. The gray shades indicate the time of the measurement (min), as shown in the legend. (b) Logarithmic plot of measured relative penetration resistance $F(t)$ and modeled relative bond-to-grain ratio $R(t)$ with $t$. Measured $F(t)$ (circles), an empirical log-linear fit with a slope of 0.22 (dashed line) and modeled $R(t)$ (black line) are shown.

there was a significant correlation between $b$ and $\rho_{\text {snow }}$ (Pearson $r=0.76, p=10^{-4}$ ). However, when omitting the snow samples consisting of DF, $b$ and $\rho_{\text {snow }}$ were uncorrelated (Pearson $r=0.29, p=0.31$ ), as was also the case for the modeled sintering rates (Pearson $\rho=-0.05, p=0.9$ ).

The influence of temperature, density and initial grain size on sintering rates was investigated in more detail by performing additional numerical simulations. We used $\left(r_{\mathrm{b}} / r_{\mathrm{g}}\right)_{\text {ini }}=0.04$, corresponding to the mean estimated initial bond-to-grain ratio for the simulations relating to the experiments (Table 1). Modeled sintering rates decreased with increasing density, decreasing temperature and increasing initial grain radius (Fig. 4). Overall, the strongest dependency was found between $b_{\text {model }}$ and $r_{\mathrm{g} \text {, ini }}$ (Fig. 4c), while $b_{\text {model }}$ showed very little dependence on snow density (Fig. 4a).

\section{DISCUSSION AND CONCLUSION}

Sintering rates in snow were investigated by measuring changes in penetration resistance with time. Periodic SMP measurements were performed on uniform snow samples covering a wide range of densities and three grain forms. Despite careful sample preparation, scatter in the measured force signals with depth (Fig. 2a) highlights the difficulty in
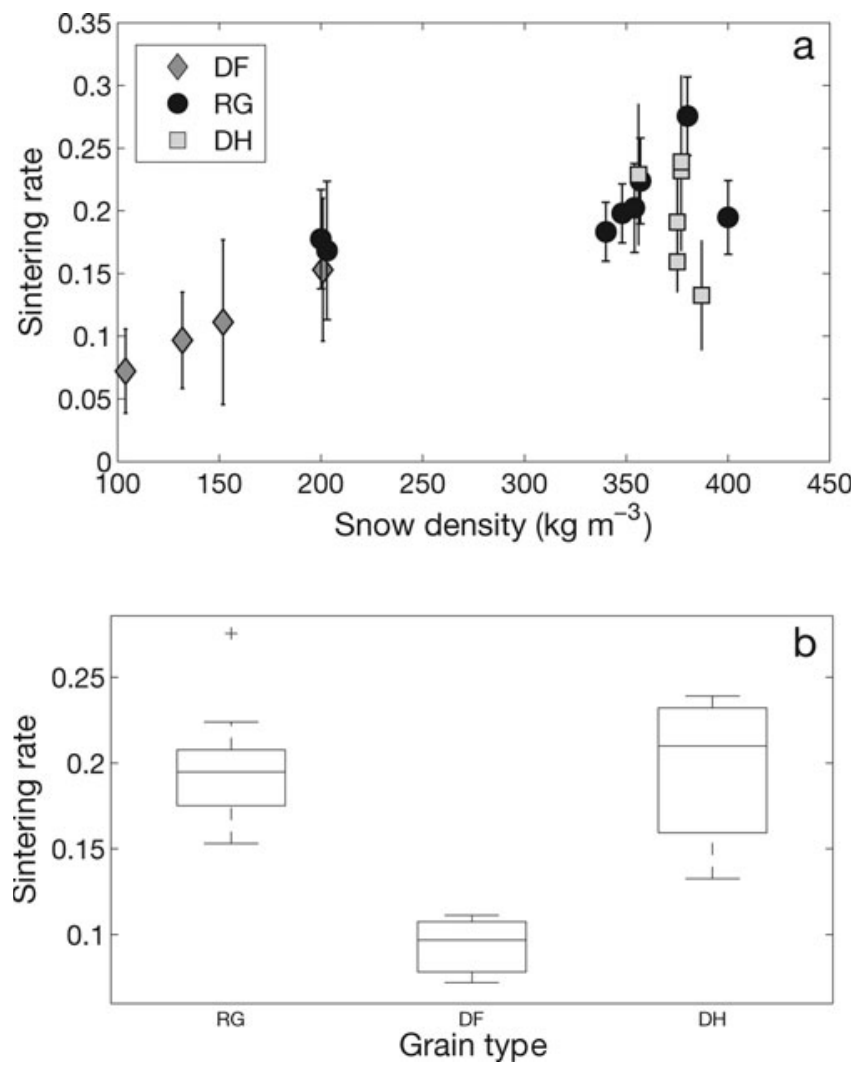

Fig. 3. Sintering rate $b$ with snow density and grain type. (a) Sintering rate with snow density $\rho_{\text {snow }}$. The different symbols and gray shades indicate the grain type of the snow sample, as shown in the legend. (b) Sintering rate with grain type. On each box, the central line is the median, the edges of the box are the 25th and 75th percentiles, the whiskers extend to the most extreme data points not considered outliers, and outliers are plotted individually as crosses.

creating truly homogeneous snow samples. However, SMP force signals recorded in natural snow layers generally also exhibit similar fluctuation (e.g. Satyawali and Schneebeli, 2010), except for force signals recorded in soft fresh snow not affected by wind. Furthermore, the SMP measurements were of good quality, comparable to those reported by others (e.g. Pielmeier and Schneebeli, 2003), and the results show that the average penetration resistance increased with time. Trends in the mean relative penetration resistance with time were undeniable (Fig. 2b) and corresponded well with modeled sintering rates (Table 1 ).

During our experiments, snow density remained essentially constant as we did not observe any measurable snow settlement. Furthermore, it is assumed that changes in grain form and size were likely small, when compared to the growth of bonds (Miller and others, 2003), since snow metamorphism is relatively slow at a constant temperature of $-10^{\circ} \mathrm{C}$ (except perhaps for the more dendritic snow samples). For rounded grains, Miller and others (2003) estimate an $8 \times$ reduction in metamorphic rates when temperature varies from 0 to $-20^{\circ} \mathrm{C}$, and significantly higher bond than grain growth rates. Therefore, intergranular bonding was a significant first-order parameter that substantially changed within the relatively short experimental timescales. We therefore believe that despite the complex interaction between the SMP and snow, the measured increases in mean penetration resistance can largely be attributed to sintering. 

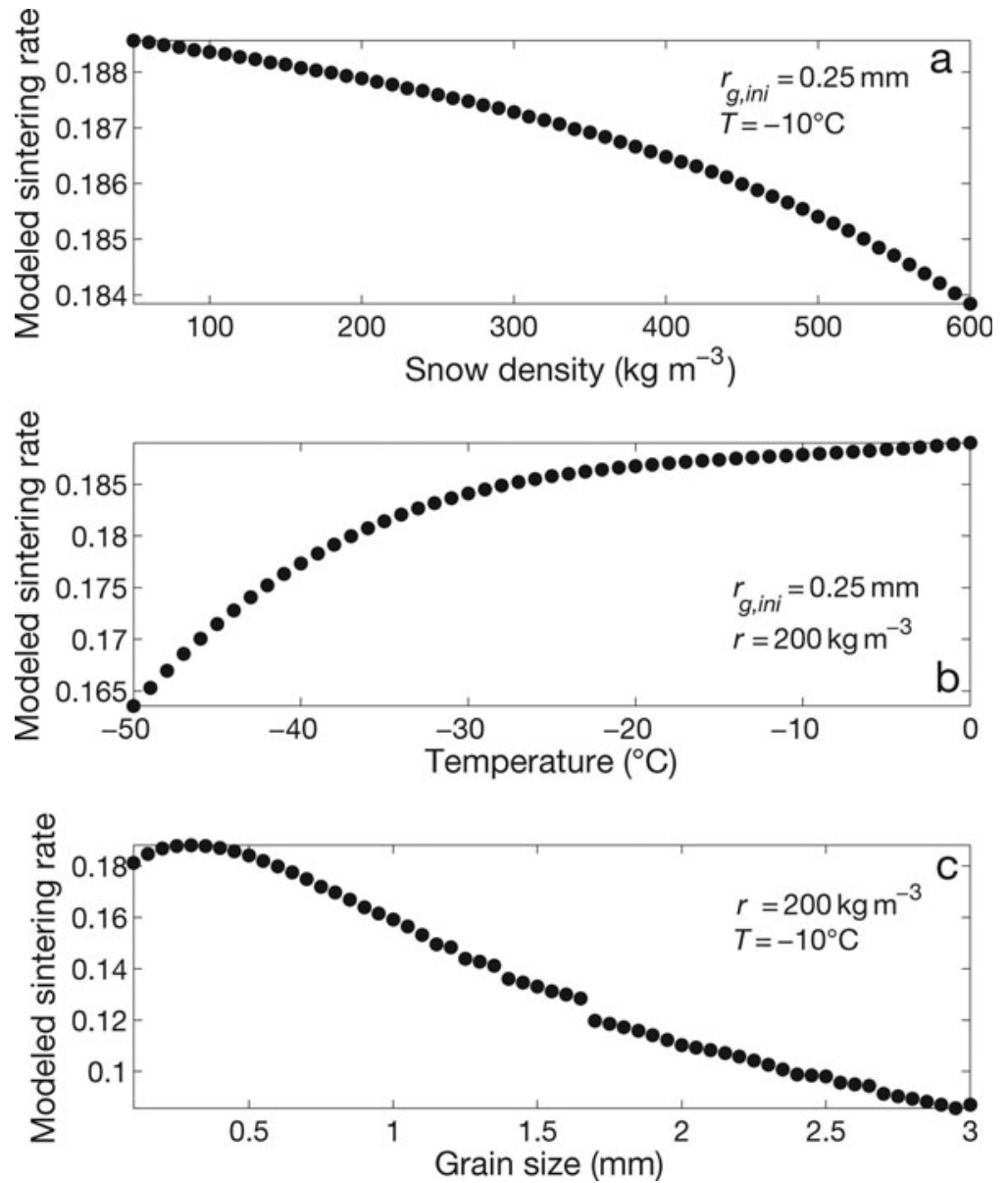

Fig. 4. Modeled sintering rate $b_{\text {model }}$ with (a) snow density $\rho_{\text {snow, }}$ (b) temperature $T$ and (c) initial grain size $r_{\mathrm{g}}$.

The largest differences between measured and modeled sintering rates were for lower-density snow samples. This comes as no surprise since the model utilizes a simplified spherical geometry for the snow grains and concave interconnecting bonds between the grains (Miller and others, 2003). Our low-density snow samples consisted mostly of dendritic snow morphologies. The lower sintering rates associated with these samples are therefore likely the result of two competing processes: (1) strengthening of the snow sample due to the creation and growth of bonds and (2) weakening of the snow sample due to the formation of unbonded small rounded particles at the expense of larger dendritic forms. This explains the observed increase in sintering rate with density for snow samples below $200 \mathrm{~kg} \mathrm{~m}^{-3}$ (grey diamonds in Fig. 3), since the initial fraction of rounded particles likely increased with increasing density. Interestingly, the sintering rates for snow samples consisting of sieved depth hoar were similar to those of rounded grains (Fig. 3). This shows that despite the larger specific surface area of angular snow crystals, the sintering rate for sieved depth hoar is similar to that of sieved rounded grains, for the crystal sizes and timescales investigated.

It has long been known that there is a strong correlation between the mechanical properties of snow and density (e.g. Mellor, 1975). It therefore comes as no surprise that the initial mean penetration resistance increased with density (Fig. 1), very similar to the results reported by Keller and others (2004). However, the question remains, what mechanical property relates to SMP force measurements? A theory was developed to derive microstructural snow properties from SMP force signals (Johnson and Schneebeli, 1999; Marshall and Johnson, 2009; Löwe and van Herwijnen, 2012). The theory is based on the premise that the measured force signal is a superposition of elastic-brittle failures of individual snow microstructural elements and friction between the snow and the penetrometer. Our measurements show that the mean penetration resistance of snow increased with time according to a power law with an average exponent of $0.18 \pm 0.05$ within the relatively short experimental timescales. This is very similar to the data on the increase in compressive strength of snow reported by Jellinek (1959), which conform to a power law with an exponent around 0.21. Furthermore, Hobbs and Mason (1964) determined experimental exponents between 0.16 and 0.24 for the growth of bonds between ice spheres. Hobbs and Mason (1964) showed analytically that in snow the bond-to-grain ratio should change with time according to a power law $t^{1 / 5}$, while the modeled changes in bond-tograin ratio followed a power law with an average exponent of $0.18 \pm 0.01$. The good agreement with our measured exponents shows that the mean penetration resistance, as measured with the SMP, is related to bond-to-grain ratio in snow. This is in agreement with the fundamental assumption for interpreting SMP force signals.

Using the physical numerical model, the influence of temperature, density and initial grain size on sintering rates was investigated in more detail (Fig. 4). The model shows that for typical temperatures and densities encountered in a seasonal snow cover, sintering rates remain relatively constant. Increases in grain size, on the other hand, can 
result in much lower sintering rates due to lower surface energy of larger grains. This is consistent with field observations showing that even when subjected to small temperature gradients, the hardness of layers consisting of large (several $\mathrm{mm}$ ) depth hoar generally does not change appreciably with time. On the other hand, layers of small rounded grains generally gain strength much more rapidly. This seems to be in direct contrast with our results, which suggest that sintering rates for depth hoar are similar to those of rounded grains. However, in our experiments depth-hoar grains were relatively small, sieved and closely packed, favoring rapid sintering. Our depth-hoar samples therefore have no clear analogy in nature, expect perhaps after an avalanche or artificial compaction due to, for instance, boot packing or grooming.

While more data are needed, our results show that sintering rates in snow are consistent with theoretical predictions, except for dendritic snow forms. An important implication of our work is that during the first hours of sintering, snow sintering rates will conform to a power law $t^{1 / 5}$ in a variety of conditions, including the hardening of freshly groomed ski trails, avalanche debris, snow plow debris, new wind drifts or sieved snow samples. On average, the penetration resistance of our snow samples doubled within an hour, while a threefold increase was only observed after 6-7 hours. In order to study snow sintering rates more systematically, additional experiments are needed, specifically on samples consisting of new snow or large grains. Alternatively, more realistic dendritic geometries could be incorporated in the model.

\section{ACKNOWLEDGEMENTS}

We thank three anonymous reviewers for comments which helped improve the paper. Financial support for this work was provided by a fellowship for advanced researchers from the Swiss National Science Foundation (grant PA00P2_131462) and by the US National Science Foundation (grant EAR-1014497).

\section{REFERENCES}

Adams EE, Miller DA and Brown RL (2001) Grain boundary ridge on sintered bonds between ice crystals. J. Appl. Phys., 90(11), 5782-5785

Adams EE, Jepsen SM and Close B (2008) A bonding process between grains in mechanically disaggregated snow. Ann. Glaciol., 48, 6-12 (doi: 10.3189/172756408784700770)

Birkeland KW, Kronholm K, Logan S and Schweizer J (2006) Field measurements of sintering after fracture of snowpack weak layers. Geophys. Res. Lett., 33(3), L03501, (doi: 10.1029/ 2005GL025104)

Blackford JR (2007) Sintering and microstructure of ice: a review. J. Phys. D, 40(21), R355-R385 (doi: 10.1088/0022-3727/40/21/ R02)

Bones J and Adams EE (2009) Controlling crystal habit in a small scale snowmaker. In Schweizer J and van Herwijnen A eds. Proceedings of the International Snow Science Workshop, 27 September-2 October 2009, Davos, Switzerland. Swiss Federal Institute for Forest, Snow and Landscape Research, Davos, 67-71

Chen S and Baker I (2010) Structural evolution during ice-sphere sintering. Hydrol. Process., 24(14), 2034-2040 (doi: 10.1002/ hyp.7787)
Colbeck SC (1998) Sintering in a dry snow cover. J. Appl. Phys., 84(8), 4585-4589 (doi: 10.1063/1.368684)

Fierz C and 8 others (2009) The international classification for seasonal snow on the ground. UNESCO-International Hydrological Programme, Paris (IHP-VII Technical Documents in Hydrology 83)

Gow AJ (1975) Time-temperature dependence of sintering in perennial isothermal snowpacks. IAHS Publ. 114 (Symposium at Grindelwald 1974 - Snow Mechanics), 25-41

Hobbs PV and Mason BJ (1964) The sintering and adhesion of ice. Philos. Mag., 9(98), 181-197

Jellinek HHG (1959) Compressive strength properties of snow. J. Glaciol., 3(25), 345-354

Johnson JB and Schneebeli M (1999) Characterizing the microstructural and micromechanical properties of snow. Cold Reg. Sci. Technol., 30(1-3), 91-100

Kaempfer TU and Schneebeli M (2007) Observation of isothermal metamorphism of new snow and interpretation as a sintering process. J. Geophys. Res., 112(D24), D24101 (doi: 10.1029/ 2007JD009047)

Keller T, Pielmeier C, Rixen C, Gadient F, Gustafsson D and Stähli M (2004) Impact of artificial snow and ski-slope grooming on snowpack properties and soil thermal regime in a sub-alpine area. Ann. Glaciol., 38, 314-318 (doi: 10.3189/ 172756404781815310)

Kingery WD (1960) Regelation, surface diffusion, and ice sintering. J. Appl. Phys., 31(5), 833-838

Kuczynski GC (1949) Self-diffusion in sintering of metallic particles. Trans. AIME, 185, 169-178

Löwe $\mathrm{H}$ and van Herwijnen A (2012) A Poisson shot noise model for micro-penetration of snow. Cold Reg. Sci. Technol., 70, 62-70

Maeno N and Ebinuma T (1983) Pressure sintering of ice and its implication to the densification of snow at polar glaciers and ice sheets. J. Phys. Chem., 87(21), 4103-4110 (doi: 10.1021/ j100244a023)

Marshall HP and Johnson JB (2009) Accurate inversion of highresolution snow penetrometer signals for microstructural and micromechanical properties. J. Geophys. Res., 114(F4), F04016 (doi: 10.1029/2009JF001269)

Mellor M (1975) A review of basic snow mechanics. IAHS Publ. 114 (Symposium at Grindelwald 1974 - Snow Mechanics), 251-291

Miller DA and Adams EE (2009) A microstructural dry-snow metamorphism model for kinetic crystal growth. J. Glaciol., 55(194), 1003-1011 (doi: 10.3189/002214309790794832)

Miller DA, Adams EE and Brown RL (2003) A microstructural approach to predict dry snow metamorphism in generalized thermal conditions. Cold Reg. Sci. Technol., 37(3), 213-226 (doi: 10.1016/j.coldregions.2003.07.001)

Nakamura H (1978) New apparatus to produce fresh snow. Rep. Nat. Res. Cent. Disaster Prev. 19, 229-237 [in Japanese with English summary]

Pielmeier C and Schneebeli M (2003) Stratigraphy and changes in hardness of snow measured by hand, rammsonde and snow micro penetrometer; a comparison with planar sections. Cold Reg. Sci. Technol., 37(3), 393-405

Satyawali PK and Schneebeli M (2010) Spatial scales of snow texture as indicator for snow class. Ann. Glaciol., 51(54), 55-63 (doi: 10.3189/172756410791386544)

Schneebeli M and Johnson JB (1998) A constant-speed penetrometer for high-resolution snow stratigraphy. Ann. Glaciol., 26, 107-111

Szabo D and Schneebeli M (2007) Subsecond sintering of ice. Appl. Phys. Lett., 90(15), 151916 (doi: 10.1063/1.2721391)

Van Herwijnen A, Bellaire S and Schweizer J (2009) Comparison of micro-structural snowpack parameters derived from penetration resistance measurements with fracture character observations from compression tests. Cold Reg. Sci. Technol., 59(2-3), 193-201 (doi: 10.1016/j.coldregions.2009.06.006) 